\title{
Earth Sciences
}

2014; 3(3): 68-75

Published online June 30, 2014 (http://www.sciencepublishinggroup.com/j/earth)

doi: $10.11648 /$ j.earth.20140303.11

\section{Rotation forcing of tectonics and climate}

\author{
Valentin Krassilov*, Sophia Barinova, Svyatoslav Rybnikov
}

Inst. of Evolution, University of Haifa, Haifa, Israel

Email address:

vakrassilov@gmail.com (V. Krassilov),barinova@research.haifa.ac.il (S. Barinova), rybnikov@ukr.net (S. Rybnikov)

\section{To cite this article:}

Valentin Krassilov, Sophia Barinova, Svyatoslav Rybnikov. Rotation Forcing of Tectonics and Climate. Earth Sciences. Vol. 3, No. 3, 2014, pp. 68-75. doi: 10.11648/j.earth.20140303.11

\begin{abstract}
Contrary to predictions of the tidal torque model, length of day (LOD) decreases over a series of fluctuations since 1960s at least. The so far deepest LOD depression of $1997-2010$ corresponds to the most prominent rises of total seismic activity and global mean temperatures. A conspicuously flat interval of the LOD curve uniformly at or slightly below $-0.1 \mathrm{~ms}$ level in $2001-2005$ roughly coincides with the similarly flattened high plateaus of total seismicity $(2002-2008)$ and temperature anomalies $(2002-2007)$, indicating causal relationships. Pearson correlation coefficients about $-0.5(\mathrm{p} \approx$ $0.03)$ for both $\mathrm{LOD} /$ earthquake frequencies and LOD/temperature anomalies are raised to $-0.76(\mathrm{p}=0.002)$ and $-0.71(\mathrm{p}=$ 0.001) respectively on supposition of about two year lag between rotation forcing and the maximal geophysical effects. Non-random earthquake frequency distribution between the geoid rises and depressions is clear evidence of rotation forcing, with about $60 \%$ significant earthquakes over the highest equatorial Papua - Solomon Islands rise. The world largest ophiolite massive in the central part of the rise marks the area of mantle upheaval, coinciding with the "critical Niño3.4 region' of operational WMO definitions. El Niño years prevail over the high plateau of temperature dynamics. These observations are meaningful in respect to the model of rotational forcing at the base of concerted global change. The mass/angular momentum transfer with magmatic activity is seen as a stabilizing feedback, with a lag about 2.5 years preliminarily inferred from a case study of El Niño /Mount Etna eruption dynamics.
\end{abstract}

Keywords: Earth's Rotation, Earthquakes, Temperature Anomalies, Volcanism, Global Change

\section{Introduction}

The tidal torque model postulates a unidirectional decelerated of Earth's rotation velocity, thereby not a factor of periodic geodynamic processes. The so-called non-tidal acceleration results from a variety of potential geodynamic factors affecting the Earth's angular momentum through mass transfer in the external geospheres and interior (comprehensively reviewed in [1]. Currently, the tidal friction cumulative effect is held to be appreciably reduced by occasional high magnitude earthquakes [2]. The possibility of earthquakes being a consequence rather than cause of rotational perturbations remains unexplored. The relationships of tectonic processes to global climate change are scarcely if at all discussed, and the latter is preferentially ascribed to technogenic greenhouse effect, therefore irrelevant to climatic periodicity of pre-industrial times.

Recently we have published on correlation of sea level and geomagnetic field reversals (a proxy of earth rotation) confirming the significance of rotation forcing for concerted global change [3], and the last decade tectonic - climatic events, although of a different time scale, seem in general agreement with this conclusion. Here our analysis refers to an admittedly too short time interval for extrapolating over geological history, but of extraordinary significance, marked by a clearly defined acceleration of Earth rotation (shortening of the length of day), thus deserving special attention from geodynamic perspectives.

\section{Material and Methods}

The conceptual background of this work is the rotation model of global change [3-6]. A derived model of synchronous rotation forcing of tectonic and climatic events is here tested in respect to chronological correlation of the Earth rotation dynamics, earthquakes, and climatic periodicity through the last decades of a marked global change. The data on the length of day fluctuations, earthquake occurrences and temperature anomalies are borrowed from dedicated Internet sources. Geological information for case studies is from regional summaries in $[6,7]$. Statistic correlation is applied in order to check upon the visual chronological relationships the data represent. 


\section{Results}

The following results are obtained for a short but outstanding period, 1993 - 2013, at the beginning of the 5th 400-year cycle CE marked by significant astronomic, geophysical, and global climate changes. This is also the period of considerable advancement in precision of instrumental observations, in particular relevant to the LOD dynamics, but also to earthquake information, as well as the regional coverage of the climate change records.

The yearly length of day (LOD) deviation from the International System of Units (SI) day of the atomic time metrics [8] (Fig. 1) shows a shortening tendency from 1960s, countering the cumulative effect of leap second (red line) introduced on assumption of a steady tidal deceleration. Zero deviation is reached in $1984-1988$, followed by interim peak in 1992 - 1996, and then shortened to the period minimum in late 1900s - early 2000s. Year minima fall down to zero line in 1998, below $-0.1 \mathrm{~ms}$ in $2003-2005$ and nearly so again in 2010 . The moving average is below $+0.1 \mathrm{~ms}$ for the entire acceleration episode from 1998 to 2010 - a noticeable acceleration of Earth rotation rates, sharply ascending almost to $+0.1 \mathrm{~ms}$ in 2006, and gently sloping down since, with 2010 conspicuously indented. The focus of the present study is the so far deepest LOD depression with near even yearly values at or below $-0.1 \mathrm{~ms}$ in $2001-2005$ and the geotectonic - climatic correlates.

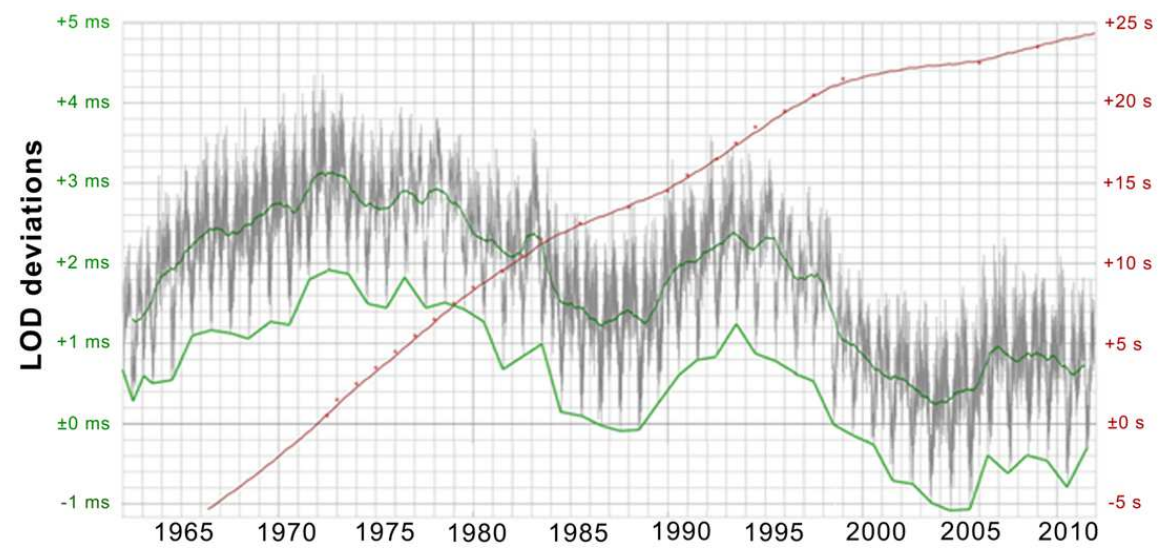

Figure 1. LOD dynamics after [8], green line the moving LOD minimum, red line the leap second effect.

Seismic activity is an expected LOD correlate on understanding that fluctuations of the earth rotation rates are source of dynamic stresses and subcrustal mass transfer mainly related to polar flattening, equatorial bulging, and zonal rotation of viscous mantle. Fig. 2 shows fluctuation of the total per year earthquake frequencies [9], featuring a nearly symmetrical rise in seismic activity through 1997 2010, with a high frequency plateau in $2002-2008$, slightly indented in 2006. The peak activities emerge above the moving average in 1998, 2003, and 2010, thus showing obvious negative correlation with the LOD dynamics (above). Pearson correlation coefficient -0496 is significant at $\mathrm{p}=0.035$.

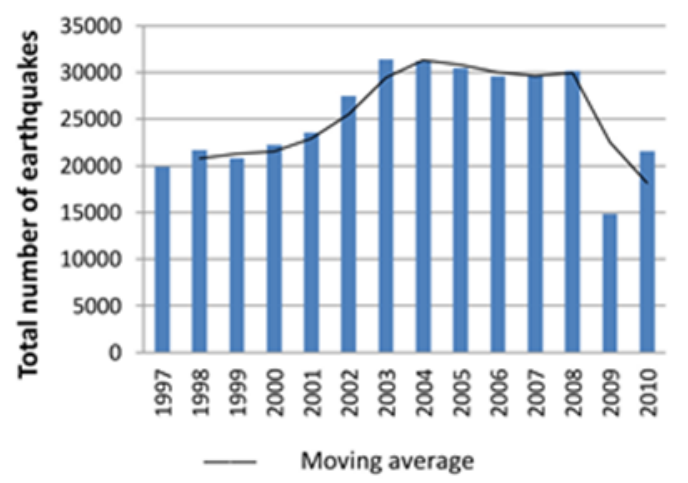

Figure 2. Annual dynamics of total seismic activity, data from [2].
A different frequency distribution is obtained for great earthquakes (NEIC ComCat), magnitude 7+ (Fig. 3) and significant earthquakes [10], magnitude 4.5+ (Fig. 4), with peaks skewed to the years $1999-2000$ and $2009-2011$, and with a low in 2004 - 2006. For these categories, correlation with LOD is statistically insignificant contrary to [2] postulate (of great earthquake effect on Earth's rotation), although the moving average drop corresponding to a sharp LOD increase in 2006 is fairly conspicuous in both.

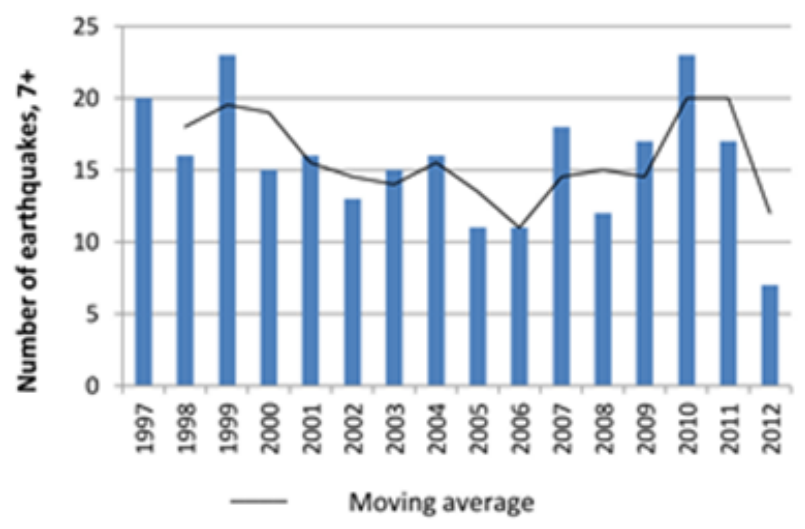

Figure 3. Annual dynamics of great (magnitude 7+) earthquakes, data from [9]. 


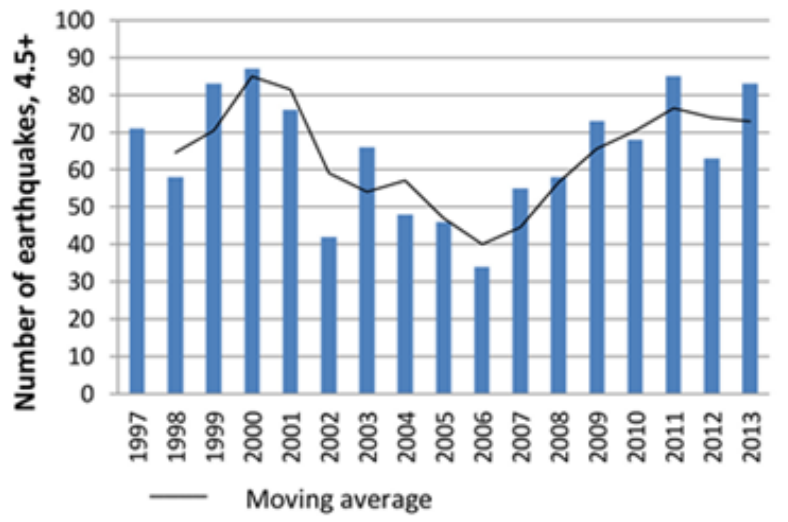

Figure 4. Annual dynamics of significant earthquakes, magnitude 4.5+ [10].

In Fig. 5, the chronological sequence of the earthquake frequency estimates is shifted ahead of the LOD chronology on supposition of a lag between rotational stimulus and tectonic response. Two years shift yielded the highest Pearson coefficient and most significant correlation $-0.76, p=0.002$, which gives a crude estimate of the tectonic lag (discussed later in the paper).

Because geoid is a geometric display of the rotation stress field configuration (Fig. 6), a non-random distribution of earthquake frequencies over the geoid rises and depressions ([11], Fig. 7) is evidence of rotation forcing. For major earthquakes of magnitude $6+$, it is obviously non-random with about $74 \%$ occurring on the rises (Fig. 7a) The highest equatorial Papua - Solomon Islands bulge, about $+100 \mathrm{~m}$, captures near $60 \%$ this category earthquakes within the $+20 \mathrm{~m}$ contour and no less than $45 \%$ inside the +40 contour alone, whereas depressions below $-20 \mathrm{~m}$ and the near zero profile between $+20 \mathrm{~m}$ and $-20 \mathrm{~m}$ ('others', including the longer segments of mid-ocean rises), account for about $9 \%$ and $17 \%$, respectively. Adding moderate earthquakes of $4+$ magnitudes gives a less contrasted distribution, but still strongly skewed toward the rises (Fig. 7b).

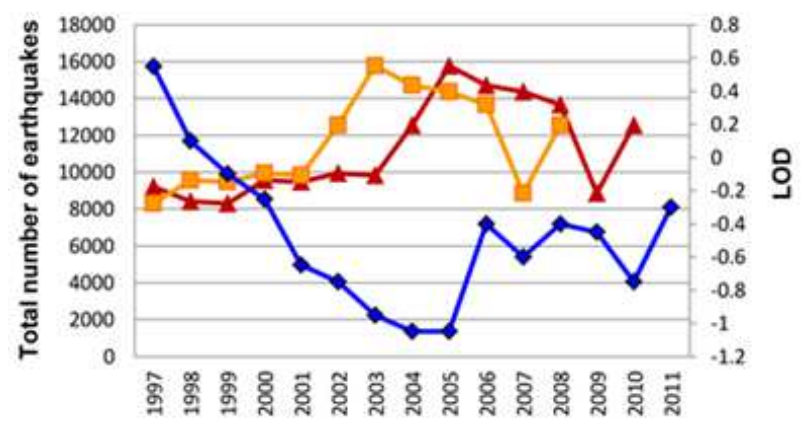

Figure 5. Annual dynamics of LOD (blue) compared with chronologically corresponding total earthquake frequencies (red) and displaced on supposition of a two year lag (orange).

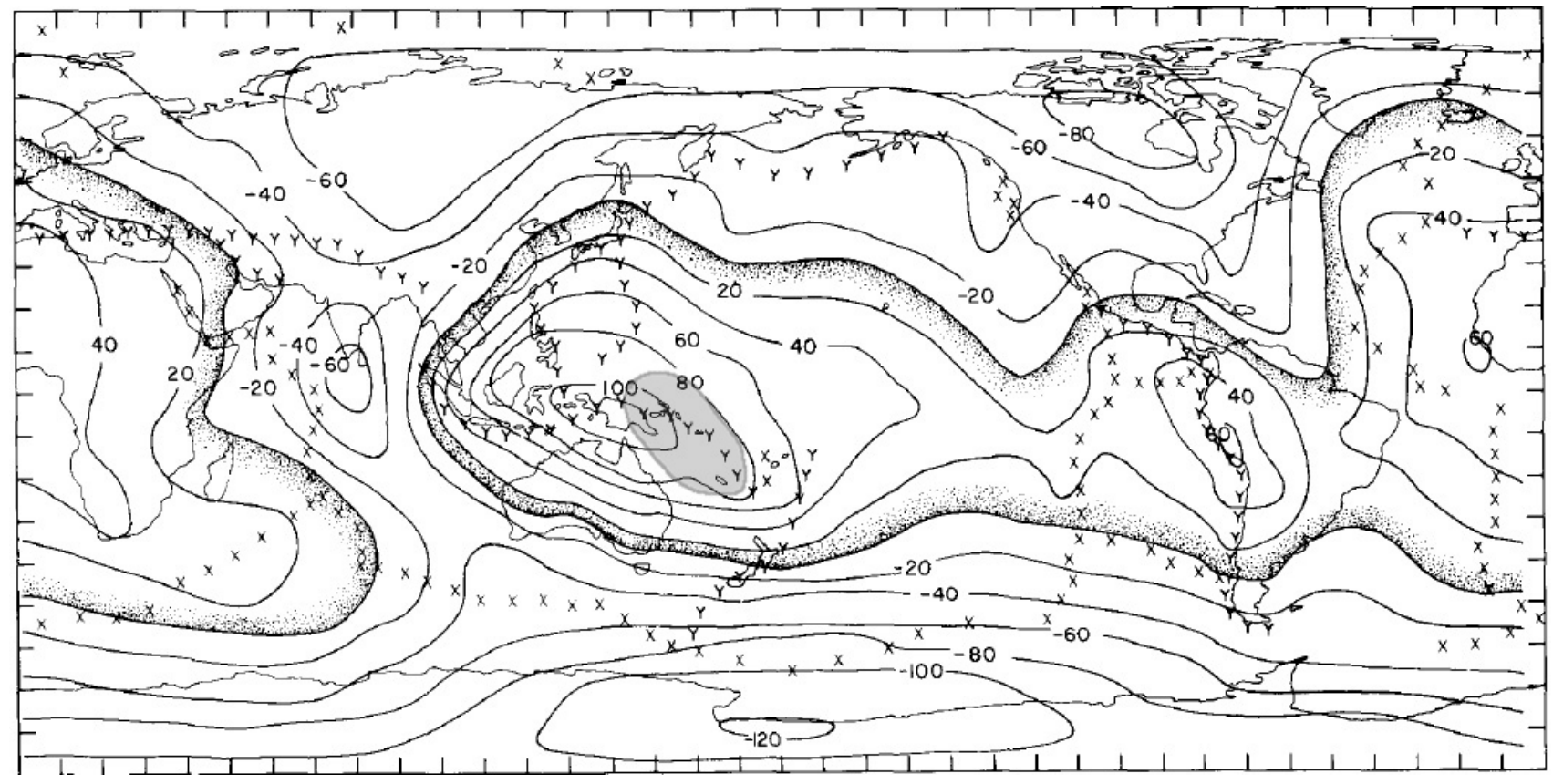

Figure 6. Geoid after [11], rises boldly countered; shaded area marks the Papua-Solomon Islands - New Caledonia ophiolite massive of the highest geoid rise. 

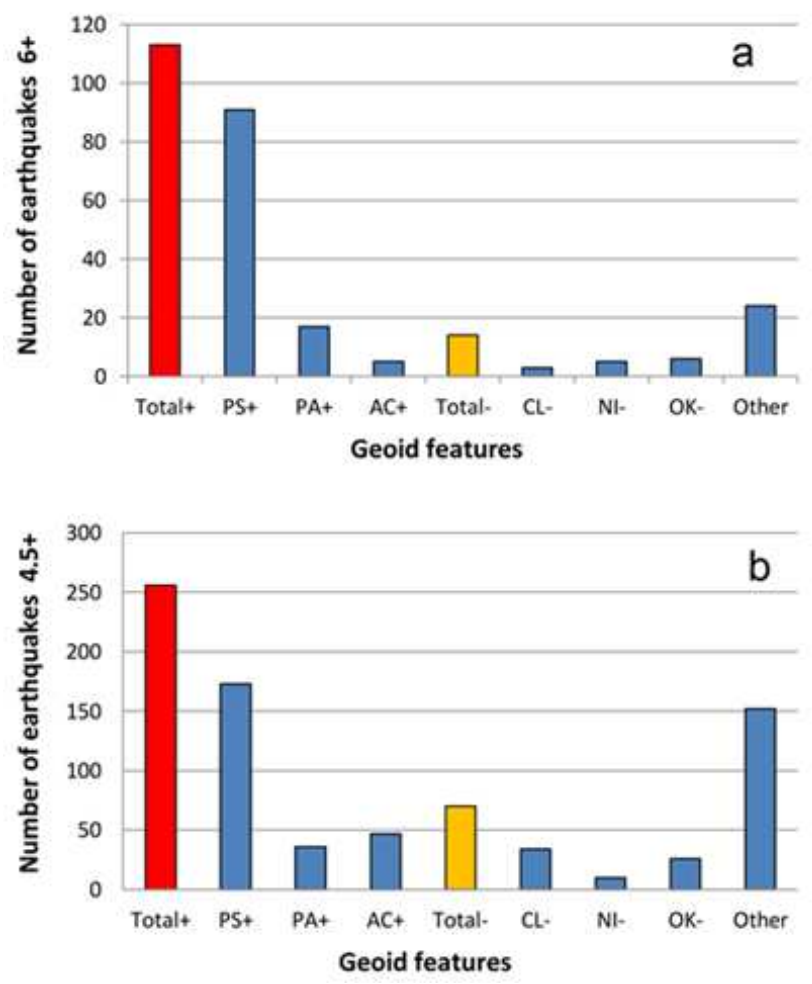

Figure 7. Earthquake distribution over rises and depressions of the geoid; A, for major (magnitude 6+) earthquakes); B, for significant (magnitude 4.5+) earthquakes. Rises(+): Ps, Papua - Solomon islands, PA, PeruAtacama; AC, African - Caspian. Depressions (-): Cl, Californian, NI, Northern Indian Ocean; Ok, Okhotsk - Kuril Islands.

The annual global temperature anomalies, $\Delta \mathrm{T}[12]$ show a definite ascending tendency since 1978 (global warming of the popular greenhouse model), but actually reaching a high plateau with minor fluctuations in $1998-2010$ (Fig. 8), possibly extended to 2013 over the interim $2011-2012$ depression (but the data for the last two years are inconclusive so far). The warmest years on all ranking are 2010 and 2005, the next ranks down being variously assigned to 2007, 1998; 2002, 2003, 2009 and 2013. Anyway, the $2002-2007$ interval is a fairly uniform part of the plateau.

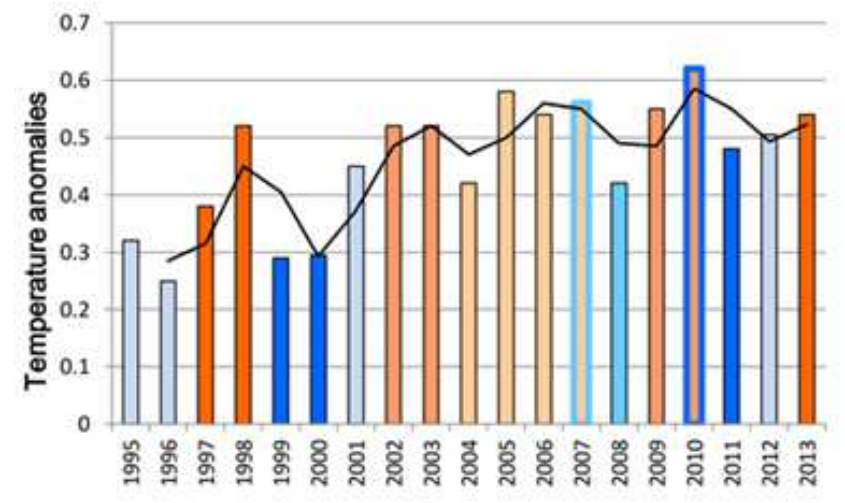

Figure 8. Annual global temperature dynamics; El Niño years yellow to orange (moderate to strong), La Niña years shades of blue, transitional years yellow/blue, data from [12, 15].
Chronological correlation of high temperature plateau with the LOD minimum over late 1900s - early 2000s (Figs. 1 , 9) is fairly obvious, with 1998, 2003, 2005, and 2010 warming events corresponding to prominent LOD drops. The $2002-2007$ high $\Delta \mathrm{T}$ interval roughly corresponds to the $2001-2005$ low LOD interval. The $\Delta \mathrm{T}$ to $\Delta \mathrm{LOD}$ Pearson correlation coefficient $-0.470(\mathrm{p}=0.038)$ is enhanced to $-071(\mathrm{p}=0.001)$ with the chronological $\Delta \mathrm{T}$ sequence shifted two years ahead of $\triangle$ LOD sequence (Fig. 9) which is the same lag effect as detected above for the LOD/earthquake dynamics, thus linking the $\Delta \mathrm{T}$ and seismic maxima.

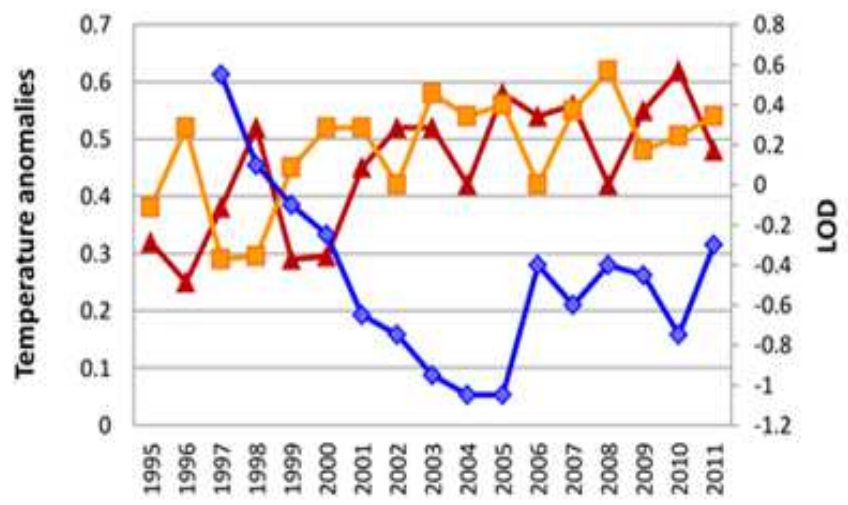

Figure 9. Annual dynamics of LOD (blue) compared with chronologically corresponding temperature anomalies (red) and displaced on supposition of a two year lag (orange).

It is well known that surface water temperature fluctuations and associated atmospheric pressure gradients in equatorial Pacific (El Niño - Southern Oscillations, ENSO) have a profound effect on the temperature precipitation dynamics worldwide. The El Niño/La Niña events are defined as the positive/negative sea surface temperature anomalies against the 1971 - 2000 period norm for equatorial Pacific, formally characterized by $0.5^{\circ} \mathrm{C}+/ 0.5 \mathrm{C}$ - departures of three-month moving averages calculated for the 'critical Niño3.4 region', $120{ }^{\circ} \mathrm{W}-$ $170^{\circ} \mathrm{W}, 5^{\circ} \mathrm{N}-5^{\circ} \mathrm{S}$ [13]. On annual scale, the anomalies are defined as El Niño or La Niña conditions when lasting more than 7 (10) consecutive months [14-16]. Otherwise situation is considered to be 'neutral', which does not mean 'non-consequential' in climatic terms.

When moderate to strong El Niño - La Niña episodes are plotted against the annual temperature anomalies (Table 1, Fig. 8), the whole high temperature plateau falls under the prevalence of El Niño, most forcefully displayed in 1998, 2002 - 2003, 2005, 2009, and 2013, while indented at the La Niña 1999 - 2001, and 2007 - 2008, and 2011 - 2012 episodes. Years 2007, 2010 and 2013 are marked by sharp transition from El Niño to La Niña regime, and 2006 has started with a strong La Niña. Thus ENSO is a decisive factor of global temperature anomalies and a potential causal link under the tectonic - climatic correlations (see under Discussion). 
Table 1. Recent El Niño/ La Niña years [15]

\begin{tabular}{lll}
\hline EI Niño years & La Niña years & Transition years \\
\hline $2012-2013$ & $20133-2014$ & 2013 \\
$2009-2010$ & $2010-2011$ & 2010 \\
$2006-2007$ & $2007-2008$ & 2007 \\
$2004-2005$ & Early 2006 & \\
$2002-2003$ & $2000-2001$ & \\
$1997-1998$ & $1998-2000$ & 1998 \\
\hline
\end{tabular}

As a preliminary result of an ongoing study of volcanic activity - climate change dynamics, the relationships of Etna's eruptions [17] and El Niño events recorded since 1950 [18] are shown in Table 2.

Table 2. Mount Etna eruption lags against ENSO peaks [17.18]

\begin{tabular}{|c|c|c|c|}
\hline $\begin{array}{l}\text { Eruption } \\
\text { date }\end{array}$ & $\begin{array}{l}\text { Eruption } \\
\text { VEI }\end{array}$ & $\begin{array}{l}\text { Recent El Niño's } \\
\text { peak date }\end{array}$ & Lag, years \\
\hline Nov-58 & 1 & Feb-58 & 0.75 \\
\hline Mar-59 & 1 & Feb-58 & 1.08 \\
\hline Oct-59 & 3 & Feb-58 & 1.67 \\
\hline Jan-66 & 2 & Nov- 65 & 0.17 \\
\hline Apr-71 & 2 & Nov-65 & 5.42 \\
\hline Sep-71 & 2 & Nov-65 & 5.83 \\
\hline Jan-74 & 2 & Nov-72 & 1.17 \\
\hline Sep-74 & 2 & Nov-72 & 1.83 \\
\hline Feb-75 & 1 & Nov-72 & 2.25 \\
\hline Apr-78 & 2 & Nov-72 & 5.42 \\
\hline Jul-79 & 2 & Nov-72 & 6.67 \\
\hline Jul-80 & 3 & Nov-72 & 7.67 \\
\hline Jan- 81 & 2 & Nov-72 & 8.17 \\
\hline Mar-81 & 2 & Nov-72 & 8.33 \\
\hline Nov-81 & 2 & Nov-72 & 9.00 \\
\hline Mar-83 & 1 & Jan-83 & 0.17 \\
\hline Apr-84 & 1 & Jan-83 & 1.25 \\
\hline Jul-84 & 3 & Jan-83 & 1.50 \\
\hline Mar-85 & 1 & Jan-83 & 2.17 \\
\hline Dec-85 & 1 & Jan-83 & 2.92 \\
\hline Mar-86 & 2 & Jan-83 & 3.17 \\
\hline Oct-86 & 2 & Jan-83 & 3.75 \\
\hline Mar-87 & 2 & Jan-83 & 4.17 \\
\hline Oct- 88 & 1 & May-87 & 1.42 \\
\hline Sep-89 & 2 & May-87 & 2.33 \\
\hline Dec-89 & 3 & May-87 & 2.58 \\
\hline Dec-91 & 2 & May-87 & 4.58 \\
\hline Feb-93 & 1 & Apr-92 & 0.83 \\
\hline Aug-93 & 1 & Apr-92 & 1.33 \\
\hline Jun-94 & 3 & Apr-92 & 2.17 \\
\hline Jul-01 & 2 & Nov-97 & 3.67 \\
\hline Dec-01 & 1 & Nov-97 & 4.08 \\
\hline Oct-02 & 3 & Nov-97 & 4.92 \\
\hline Mar-03 & 1 & Nov-02 & 0.33 \\
\hline Feb-04 & 1 & Nov-02 & 1.25 \\
\hline Sep-04 & 1 & May-04 & 0.33 \\
\hline Dec-05 & 1 & May-04 & 1.58 \\
\hline Jul-06 & 2 & May-04 & 2.17 \\
\hline Mar-07 & 2 & May-04 & 2.83 \\
\hline May-08 & 1 & May-04 & 4.00 \\
\hline Apr-10 & 2 & Dec-09 & 0.33 \\
\hline Aug-10 & 1 & Dec-09 & 0.67 \\
\hline
\end{tabular}

Mount Etna, Sicily occurs in the zone of high tectonic activity extending along $40^{\circ} \mathrm{N}$ over California, New Madrid Seismic Zone of United States east of Rocky Mountains, Atlantic transform faults, Mediterranean, Caspian region and Xingjian to crossing the Western Pacific belt. It is hypothetically related to rotation stresses over a mid-latitude boundary of differential angular velocity zones in the mantle, therefore indirectly corresponding to the equatorial bulge dynamics. Unlike Pinatubo eruptions for example, the Mediterranean volcanism lags appreciably behind temperature anomalies.

Plotting lags from the sea surface temperature peaks against the number of eruptions (Table 3, Fig. 10) results in exponential distribution with 2.998 , asymptotic significance 0.659 . For three of four high-explosivity (VEI=3) eruptions, extremely high negative correlation is found between the lag and El Nino's intensity (Pearson correlation coefficient -0.97 ). Summarily, the data seem to suggest a lag about 2.0 -2.5 years between the rotation driven hydrosphere and tectonosphere events involving significant subcrustal mass transfer the sequence of volcanic eruptions represents.

Table 3. Mount Etna eruptions ranked by lag and intensity

\begin{tabular}{lllll}
\hline \multirow{2}{*}{ Lag, years } & \multicolumn{5}{l}{ Number of eruptions } \\
\cline { 2 - 5 } & $\mathbf{V E}=\mathbf{1}$ & $\mathbf{V E}=\mathbf{2}$ & $\mathbf{V E}=\mathbf{3}$ & Total \\
\hline $0-1$ & 6 & 2 & 0 & 8 \\
$1-2$ & 6 & 2 & 2 & 10 \\
$2-3$ & 3 & 3 & 2 & 8 \\
$3-4$ & 0 & 3 & 0 & 3 \\
$4-5$ & 2 & 2 & 1 & 5 \\
$5-6$ & 0 & 3 & 0 & 3 \\
$6-7$ & 0 & 1 & 0 & 1 \\
$7-8$ & 0 & 0 & 1 & 1 \\
$8-9$ & 0 & 3 & 0 & 3 \\
Grand Total & 17 & 19 & 6 & 42 \\
\hline
\end{tabular}

\section{Discussion}

In the rotation model of global change [3-6], discrepant rotation velocities over major density divides in the earth crust and interior are considered to be the major cause of mass transfer resulting in concerted geomagnetic, tectonic, hydrospheric and atmospheric perturbations, with transfer of angular momentum as a stabilizing feedback. Chronological correlation of a conspicuous late 1900s - early 2000s LOD minimum with tectonic (seismic) activity and temperature anomalies in turn correlated with oceanic sea surface temperature fluctuations over the equatorial bulge of the geoid is here seen as critical evidence in favor of rotation driven global change.

This concept requires a moderate to radical revision of the current geodynamic paradigms, of which the tidal torque model of the Earth rotation dynamics is the most vulnerable in terms of theoretical premises as well as factological evidence. The tidal torque model postulates a directional deceleration of Earth's rotation rates - LOD decrease by $2.3 \mathrm{~ms} /$ century with Moon steadily recessing from the Earth. Deviations are ascribed to some poorly specified non-tidal forces [19] However, the amplitude of 'non-tidal' LOD fluctuation in 1985 - 2011 (Fig. 1) is about $5 \mathrm{~ms}$ ( +4 to $-1 \mathrm{~ms})$, more than the supposed tidal gain in LOD for two centuries, which renders the tidal effect subordinate to non-tidal forcing. 
Extrapolation of instrumental data based on satellite techniques back in time $[20,21]$ is impeded by low reliability of historic records, whereas paleontological records are biased in favor of the most distinct growth lines on epitheca of fossil corals or shell increments discernible at low magnification and arbitrary interpreted as diurnal, but in fact representing any of hierarchical periodicities from diurnal to weekly or monthly [6].

In principle, the tidal torque model is applicable not only, and not so, to hydrosphere (sea tides), but also and foremost to subcrustal surges of plastic mantle melts, the astenosphere. However, the periodicity of mantle surges seems to be of an annual rather than diurnal scale, therefore driven by Sun rather than Moon. Moon's rotation period is equalized with its revolution period, therefore locked at 27.32 days, synchronized with the synodic period of Sun rotation at the equator, 27.27 days (the sidereal period, 25.38 days). The angular momentum and the distance of Moon from the binary system barycenter is fixed making a unidirectional recession of Moon unrealistic, its gravitational effect on Earth rotation greatly overridden by the solar effect, in particular of solar wind on LOD dynamics [22] on geoselenic system as a whole, with Moon assigned a stabilizing function.

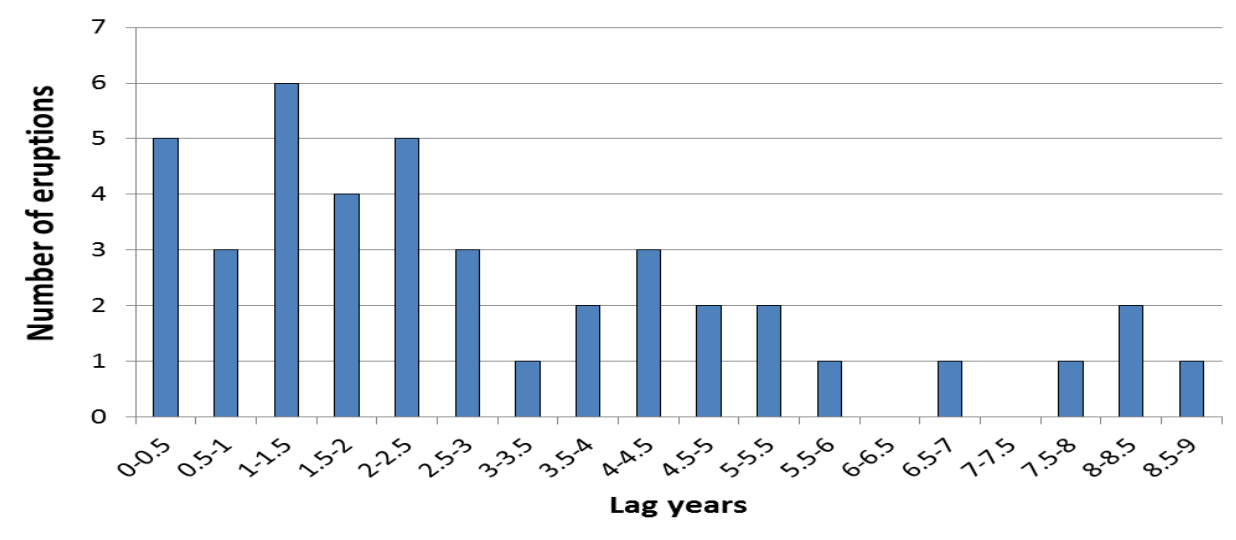

Figure 10. Mount Etna eruption frequencies ranked by the lag from El Niño peaks (Table 3).

According to the plate tectonic model, lithosphere is split into plates driven by mantle convection divided into autonomous cells that are indefinitely if at all inter-correlated. Thereby a major earthquake may happen anytime anywhere, with an erratic effect on Earth rotation ascribed to subduction of oceanic lithosphere and varying from infinitesimally small to instantaneously reducing many centuries effect of cumulative tidal deceleration [2]. However this model is contradicted by the lack of significant correlation between LOD dynamics and great earthquakes (Fig. 3), with total seismic activity lagging behind the LOD events (Fig. 2). Ophiolite assemblages are evidence of subcrustal material being extruded over deep fault zones rather than sucked in.

Moreover, the empiric correlation of the recent LOD minimum with tectonic (seismic) activity is meaningful on account of non-random earthquake distribution over rises and depression of the geoid shaped by the rotation stress field. Seismicity is greatly enhanced over the rises, in particular the most conspicuous equatorial bulge dominating the earthquake statistics (Fig. 7).

The Papua - Solomon Islands rise is the most prominent part of the Earth equatorial bulge, rising above $+100 \mathrm{~m}$ contour of the geoid relief. A giant overthrust of the Earth mantle material, the Papua - New Guinea ophiolite massive about $40 \mathrm{x} 400 \mathrm{~km}$ is the largest in the world, but only a part of the Papua - New Caledonia ophiolite belt emplaced since the Eocene $[23,24]$. About two thirds major earthquakes are confined in the $+20 \mathrm{~m}$ contour of the rise, tracing the Mariana - Tonga trenches in the east and the Palauan - Mentawai trenches in the west, likewise ophiolitic; altogether a huge mantle bulb breaking and dispersing the crustal blocks above (similarly, the Peru - Chile and Greece - Turkey Zagros rises, as well as the arcuate seismic ridges over the Californian, Aleutian and the Kuril Island depression owe their prominence in the gravity field to ophiolite emplacements (reviewed in [6]).

Since the critical El Niño region is situated over the central part of the Papua - Solomon Islands bulge, the coincidence of tectonic and hydrospheric events does not seem occasional. Sea level rise over the bulge is 17.3 $\mathrm{mm} /$ year, about ten times greater than the global average [25]. This giant pool of hot water extends and shrinks with the rise and sink of the mantle bulb beneath, with heat released through exothermic high pressure metamorphism over the flanking shear zones.

While the idea of catastrophic climate warming driven by greenhouse effect is contrary to the observed dynamics of temperature anomalies correlated with LOD and seismicity, near simultaneously ascending to a high plateau in $1998-$ 2010 (Figs. 8, 9), a predictive theory of global climate change would have take into consideration the multiple tectonic and hydrospheric effects of rotation forcing, from trend wind velocities - surface water currents and sea level fluctuations to mantle upheaval, heat release from dynamic metamorphism, and above all the periodic expansion contraction of warm water pools over equatorial bulges and the counter phase fluctuations of cool water pools over polar flattening as a major source of Southern and Arctic oscillations under the global warming/cooling tendencies. 
Both equatorial and polar oscillations scale to geoid deformation, alternately taking over as the common denominators of climatic variables, with biospheric feedbacks like the $\mathrm{CO}_{2}$ greenhouse effect.

Periodicity is evidence of stabilizing feedbacks, for which the lag of mass - angular momentum transfer relative to direct rotation forcing, such as the mid-latitude volcanic eruptions lagging behind El Niño, is one of perspective source of instructive evidence, but the inference is no more than preliminary at this stage.

\section{Conclusion}

Recent LOD minimum correlates with seismic and temperature maxima. Pearson correlation is enhanced by introducing a two year lag between the LOD depression and the high plateau seismic activity and temperature anomalies. The LOD dynamics suggests a subordinate to negligible tidal torque effect supposedly overridden by a gravitational Sun effect on the binary geoselenic system as a whole.

A LOD effect of occasional high magnitude earthquakes postulated on the basis of plate tectonic model is contradicted by the lack of significant correlation between LOD and the major earthquake dynamics. Earthquake distribution is non-random, with the total earthquake frequencies over geoid rises greatly dominating the earthquake statistics. About $60 \%$ significant earthquakes occur inside the $+20 \mathrm{~m}$ contour of the highest Papua Solomon Islands bulge, a huge mantle bulb with the world largest ophiolite massive in the central part, which is also the critical El Niño region.

The chronology of global temperature anomalies reaching an El Niño dominated high plateau in 1998 - 2010 does not agree with the idea of steady greenhouse warming. Southern oscillations at the base of the global temperature anomalies are linked to LOD and tectonic activity through the rotation driven rise/sink of the equatorial bulge and respective expansion - contraction of the central Pacific warm water pool. A lag about 2.5 years between El Niño maxima and mid-latitude volcanic eruptions (Mount Etna) gives a preliminary timing of a stabilizing mass/angular momentum transfer feedback of the rotation driven tectonic - climatic change.

\section{Acknowledgements}

We acknowledge the support of our research by VATAT, the Israeli Council for Higher Education, and the Institute of Evolution, University of Haifa.

\section{References}

[1] N. Sidorenkov, The Interaction between Earth Rotation and Geophysical Processes. Wiley-VCH, 2009, 305 pp.

[2] How the Japan Earthquake Shortened Days on Earth. SPACE.com Staff March 13, 2011. http://www.space.com/11115-japan-earthquake-shortened-ea rth-days.html.

[3] V. Krassilov and S. Barinova. Sea Level - Geomagnetic Polarity Correlation as Consequence of Rotation Geodynamics. Earth Science, Vol. 2, No. 1, 2013, pp. 1-8. doi: 10.11648/j.earth.20130201.11

[4] V.A. Krassilov, Plate tectonics and rotational dynamics of the planet. Izvestia (Proceedings) Acad. Sci. U.S.S.R, Geol., vol.1, pp. 74-82, 1976 (Rus).

[5] V.A. Krassilov, Overview of rotational geodynamics. Tikhookeanskaya Geologia (Pacific Geology), no. 1, pp. 89-95, 1991. (Rus.).

[6] V.A. Krassilov, Cretaceous Period. Evolution of Earth Crust and Biosphere. Moscow; Nauka, 1985. 240 pp. (Rus.).

[7] V.A. Krassilov, Terrestrial Palaeoecology and Global Change. Sophia: Pensoft, 2003, 464 pp.

[8] Deviation of day length from SI based day, $1962-2010$. http://en.wikipedia.org/wiki/File:Deviation_of_day_length_f rom_SI_day_.svg

[9] Earthquake Facts and Statistics, USGS, 2013. http://earthquake.usgs.gov/earthquakes/eqarchives/year/eqst ats.php.

[10] Significant Earthquakes of the World. USGS http://earthquake.usgs.gov/earthquakes/eqarchives/significa $\mathrm{nt} /$

[11] C.G. Chase and D.R. Sprowl, The modern geoid andancient plate boundaries, Earth and Planet. Sci. Lett., vol. 62, pp. 314-320, 1983.

[12] C.P. Morice, J.J. Kennedy, N.A. Rayner, and P.D. Jones, Quantifying uncertainties in global and regional temperature change using an ensemble of observational estimates: The HadCRUT4 dataset, J. Geophys. Res., vol. 117, 2012, D08101, doi:10.1029/2011JD017187

[13] Nino3.4. East Central Tropical Pacific SST (5N-5S) (170-120W).

http://www.esrl.noaa.gov/psd/data/correlation/nina34.data

[14] Catalogue of Indices and Definitions of El Niño and La Niña in Operational Use by WMO Members / WMO Commission for Climatology; CCl-XIII (2005) Expert Team on El Niño and La Niña Definitions Geneva, World Meteorological Organization, 2006. https://www.wmo.int/pages/prog/wcp/ccl/opags/opag3/docu ments/Catalogue_12062006.pdf

[15] El Nińo/Southern Oscillation (ENSO) diagnostic discussion issued by Climate Prediction Center/NCEP and the International Research Institute for climate and society, 8 May 2014. http://www.cpc.ncep.noaa.gov/products/analysis_monitoring /enso_advisory/ensodisc.html

[16] N.K. Larkin, D.E. Harrison. "On the definition of El Niño and associated seasonal average U.S. weather anomalies". Geophysical Research Letters, vol. 32 (13), L13705, 1-4. Jul. 2005.

[17] Mount Etna. Summary of eruption dates and Volcanic Explosivity Indices (VEI) // Global Volcanism Program: $\mathrm{http}: / /$ www.volcano.si.edu/volcano.cfm? vn=211060\# 
[18] Nino3.4. East Central Tropical Pacific SST (5N-5S) (170-120W):

http://www.esrl.noaa.gov/psd/data/correlation/nina34.data

[19] F.R. Stephenson, L.V. Morrison. "Long-term fluctuations in the Earth's rotation: $700 \mathrm{BC}$ to AD 1990". Philosophical Transactions of the Royal Society of London, Series A, vol. 351, pp. 165-202, 1995.

[20] R.S. Gross, Earth rotation variations - long period, in Physical Geodesy, edited by T. A. Herring, pp. 239-294, Treatise on Geophysics vol. 3, Elsevier, Oxford, 2007

[21] A.I. Arbab. "The Length of the Day: A Cosmological Perspective". Progress in Physics, ICS, vol.1, pp. 8-11, Jan. 2009.
[22] N.-A. Mörner. "Solar wind, Earth's rotation and changes in terrestrial climate". Phys. Rev. Res. Intern., vol. 3(2), pp. 117-136, 2013.

[23] J. Milsom, Papuan ultramafic belt; gravity anomalies and emplacement of ophiolitess. Bull. Geol. Soc, Amer., vol. 84, pp. 2243-2248, 1973.

[24] H.L. Davies, Crustal structure and emplacement of ophiolite in southern Papua, New Guinea. Ofioliti, vol 5, pp. 119-120, 1980 .

[25] Pacific Country Report. Sea level and climate: their present state. Papua New Guinea, AMSAT AusAID, 30 pp. June 2002. 